\title{
Er miljøgifter i norsk kosthold skadelig for barn?
}

\author{
Myndighetene viser til grenseverdier for miljøgifter når de angir sine kostholdsanbefalinger. Norske studier \\ har påvist helseskader hos barna selv om mødrene har et lavere inntak enn anbefalte grenser. Noe er åpen- \\ bart feil.
}

Bjørn J. Bolann

bjorn.bolann@helse-bergen.no

Sandra Huber

Jerome Ruzzin

Jan Brox

Henrik S. Huitfeldt

Anne-Lise Bjørke Monsen

Miljøgifter er et globalt problem og utgjør en trussel mot både dyr og mennesker (1). Skadepotensialet er særlig stort i perioder av livet da det skjer en rask vekst og utvikling, som under svangerskap og i barnealder (2). Persistente organiske miljøgifter (persistent organic pollutants, POP-er) er en fellesbetegnelse på en gruppe organiske miljøgifter som blant annet inkluderer dioksiner, polyklorerte bifenyler (PCB-er), bromerte flammehemmere og klororganiske pesticider. De nedbrytes svært langsomt, utskilles i liten grad fra eksponerte organismer og vil derfor hope seg opp i næringskjeden (bioakkumuleres). De fleste er fettløselige, og $i$ kosten finnes derfor de høyeste konsentrasjonene i fet mat, særlig i fet fisk (3), mens morsmelk er hovedkilden hos spedbarn (4). I løpet av de siste ti årene har nivået av de fleste, men ikke alle slike miljøgifter sunket i matvarer, og også i morsmelk (5).

Mange av miljøgiftene lagres i kroppens fettvev der de kan ha en halveringstid på opptil ti år. Med svangerskap og amming reduseres nivået hos kvinner (6). Men samtidig som miljøgiftnivået synker hos mor, øker det hos barnet, og den førstefødte får overført betydelige deler av morens lager av miljøgifter (7). Etter ett års amming kan nivået av enkelte miljøgifter i morsmelken reduseres med over $90 \%$ (8). I en fersk studie fant man at plasmanivået av PCB hos norske småbarn lå omtrent $40 \%$ høyere enn hos mødrene. Barnas plasmanivå var relatert til mødrenes inntak av miljøgifter gjennom kosten (9).

\section{Effekter hos barn}

Mange epidemiologiske studier har vist at miljøgifter er assosiert med både akutte og vedvarende skader på lever, nyrer, hormonsystem og sentralnervesystem $(10,11)$. Det er en sammenheng mellom pre- eller postnatal eksponering og senere negative helseeffekter hos barn. Eksponering for miljøgifter i fosterlivet og i tidlig barnealder er assosiert med nevrokognitive skader, inkludert AD/HD og autisme samt diabetes, overvekt og kreft $(12,13)$. Også kohortstudier som inkluderer norske barn, har vist negative helseeffekter relatert til inntak og nivå av miljøgifter hos mor, deriblant redusert fødselsvekt, atferdsproblemer i barnealder og redusert språkutvikling og immunrespons $(14,15)$.

Noen miljøgifter er såkalte hormonhermere (endocrine disruptors). Skadevirkningene av hormonhermere kommer allerede ved svært lave doser, og skadene kan ofte ikke forutsies ut fra studier gjort ved høyere doser (10). Eksponering for hormonhermere er blitt knyttet til overvektsepidemien, som også rammer barn og unge. Flere studier viser en sammenheng mellom maternelt nivå av ulike hormonhermere og risiko for senere overvekt hos barnet $(16,17)$.

Det er beregnet at utviklingen av fedme og diabetes på grunn av hormonhermere med moderat sannsynlighet vil koste EU over 18 milliarder euro per år (18).

En multisenterstudie som omfattet over 26000 gravide kvinner, viste at et høyt inntak av fisk under svangerskapet var assosiert med senere utvikling av overvekt hos barnet (19). Som en mulig forklaring anførte forfatterne at fisk er en betydelig kilde til miljøgifter i form av hormonhermere, og de konkluderte med at gravide kvinner burde begrense inntaket av fisk.

\section{Grenseverdier}

Toksiske ekvivalenter (TE) er et uttrykk for giftighet av dioksiner og dioksinlignende polyklorerte bifenyler (dl-PCB). Grenseverdi for tolerabelt ukentlig inntak (Tolerable Weekly Intake, TWI) av dioksiner og dl-PCB ble for 15 år siden satt til 14 pg TE per kilo kroppsvekt per uke $(5,20)$. Slike grenseverdier angir den mengden giftstoff som et menneske kan innta per uke gjennom hele livet uten antatt helserisiko. Mange andre persistente organiske miljøgifter har ingen etablert grenseverdi.

Grenseverdier basert på en livstidseksponering kan ikke si noe om hvor mye gift småbarn tåler i de første leveårene uten å ta skade. Negativ sammenheng mellom mors inntak av dioksiner og dl-PCB-er og fosterutvikling er funnet også ved lavere inntak enn tolerabelt ukentlig inntak (21). I en subgruppe fra den norske mor og barn-studien fant man at selv om 97,5\% av mødrene hadde et inntak av dioksiner og polyklorerte bifenyler under gjeldende grenseverdier, var mors inntak av disse miljøgiftene relatert til redusert immunrespons hos barna (22). Også andre studier har vist at de skadelige effektene av miljøgifter ikke sikkert kan relateres til en terskelverdi (23).

EU-kommisjonen har også grenseverdier for maksimalt tillatt innhold av enkelte miljøgifter i matvarer (24). Grenseverdiene varierer mellom ulike matvarer; grenseverdien for dioksiner og dl-PCB i fisk er dobbelt så høy som i kylling og fem ganger høyere enn i svinekjøtt, på tross av at giften er den samme. Generelt ligger innholdet i norsk mat langt under EUs grenseverdier, men noen matvarer, som fet fisk og skalldyr, inneholder forholdsvis mye mer enn andre (25-27) (fig 1). Det finnes imidlertid mer enn 100000 ulike miljøgifter, og for flertallet av disse er det ikke fastsatt grenseverdier fordi faktagrunnlaget er begrenset.

\section{Hvor mye dioksiner og dl-PCB-er får nordmenn i seg?} Folkehelseinstituttet angir at befolkningen har et beregnet gjennomsnittlig inntak av dioksiner og dl-PCB på 10 pg TE per kilo kroppsvekt per uke (5). Det er lavere enn den fastsatte grensen på 14 TE per kilo kroppsvekt per uke. Medianverdien hos norske toåringer er 18 pg TE per kilo kroppsvekt per uke, altså over grensen (5). Det høyeste inntaket av miljøgifter finner man imidlertid hos den mest sårbare delen av befolkningen. Ifølge farmakokinetiske studier kan mengden giftstoff som barn tar opp fra morsmelk, i forhold til kroppsvekten, være mange ganger høyere enn det 


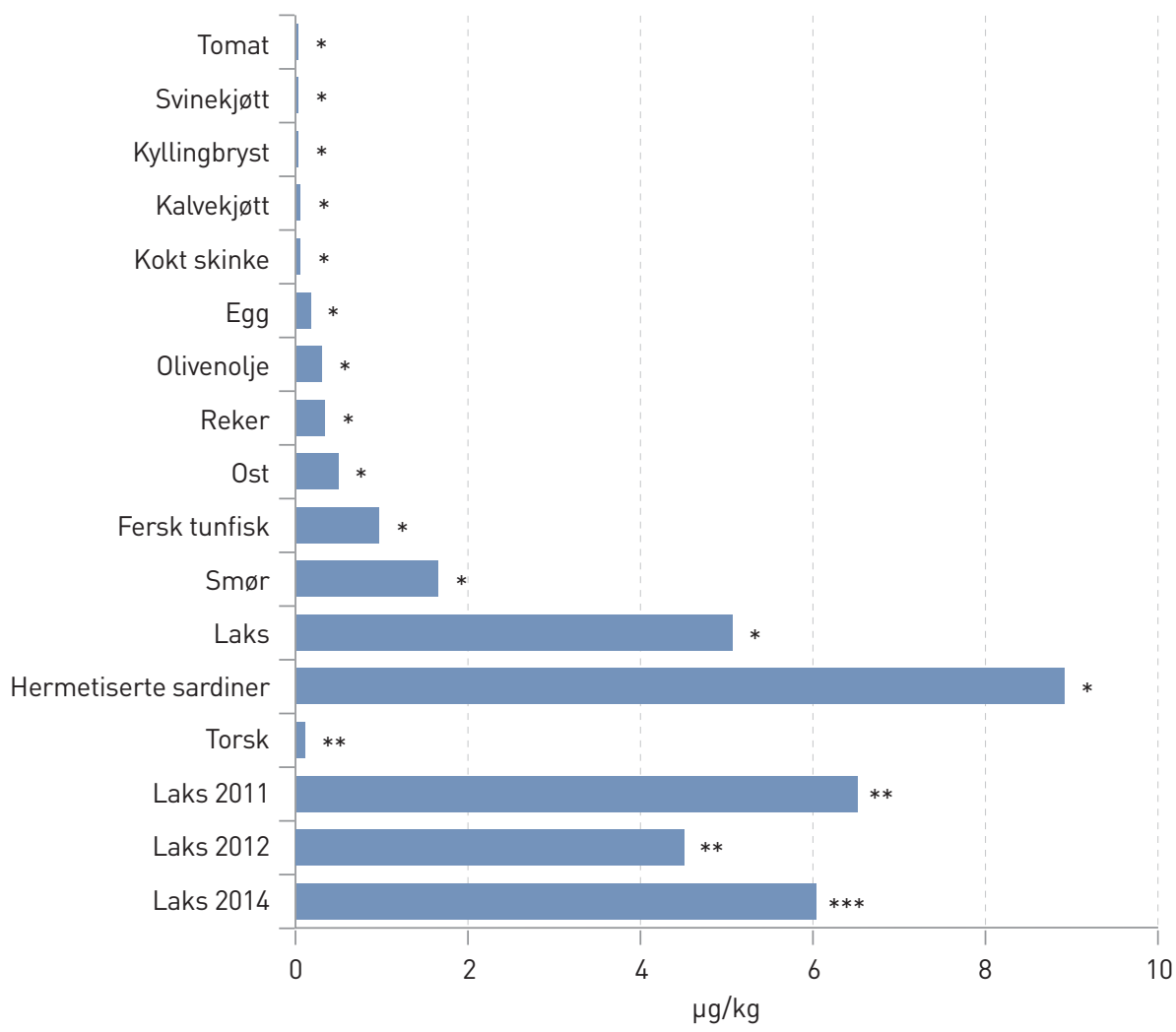

Figur 1 Sum av syv PCB-er (-28,-52, -101, -118, -138, -153 og -180) i ulike matvarer fra Catalonia, Spania 2012 (26) (*), i torsk og oppdrettslaks analysert av NIFES (27) (**) samt i gjennomsnitt for tre norske oppdrettslaks kiøpt på Marché International de Rungis, Frankrike 2014 av France 5 Television, analysert av Carso - Laboratoire Santé Environnement Hygiène de Lyon, Frankrike (***) (Baya Bellanger, Toni Comiti Productions, Paris, personlig meddelelse)

voksne tar opp fra kosten. Det er derfor foreslått å benytte en egen faktor på minimum ti ved risikovurdering hos morsmelkernærte barn (28). Denne faktoren dekker imidlertid bare farmakokinetiske forhold og tar ikke høyde for at barn er mer sårbare for giftpåvirkning enn voksne (2).

Grenseverdiene er basert på studier der man har sett på hvordan en gitt miljøgift påvirker organismen, men miljøgiftene opptrer ikke enkeltvis. Giftene tas opp og lagres i form av en blanding, noe som kan gi negative helseeffekter selv om inntak av stoffene hver for seg er under anbefalt grenseverdi (29). De første månedene etter fødselen er barnets hjerne i sterk vekst, og hjernen gjennomgår en stadig restrukturering. Samtidig får barnet overført store deler av morens akkumulerte miljøgifter, bestående av en ukjent blanding av organiske miljøgifter og tungmetaller.

\section{Egne rådgivende enheter}

Miljøgifter er en global helsemessig utfordring. I flere land er det opprettet egne enheter, Pediatric Environmental Health Specialty Units (PEHSU), som underviser og gir råd om miljøgifter og deres betydningen for barns helse (30). Det synes å være behov for en tilsvarende organisasjon i Norge.
Mange studier viser at miljøgifter kan ha negative helseeffekter hos barn, selv ved de relativt lave bakgrunnsverdiene av miljøgifter vi har i dag. Vi har i realiteten ingen mulighet for å fastsette sikre grenseverdier for miljøgifter i mat. Vi må alle arbeide for å redusere nivået av miljøgifter i mat og bidra til at befolkningen velger et kosthold med et lavest mulig innhold av giftstoffer.

\section{Bjørn J. Bolann (f. 1947)}

er spesialist $\mathrm{i}$ indremedisin og medisinsk biokjemi, professor ved Universitetet i Bergen og overlege ved Haukeland universitetssykehus. Forfatter har fylt ut ICMJE-skjemaet og oppgir ingen interessekonflikter.

\section{Sandra Huber (f. 1975)}

er spesialrådgiver ved Laboratoriemedisin, Universitetssykehuset Nord-Norge. Hun har forsket på miljøgifter i mer enn tolv år.

Forfatter har fylt ut ICMJE-skjemaet og oppgir ingen interessekonflikter.

\section{Jerome Ruzzin (f. 1976)}

er forsker i miljøtoksikologi ved Institutt for biologi, Universitetet i Bergen

Forfatter har fylt ut ICMJE-skjemaet og oppgir

ingen interessekonflikter.

\section{Jan Brox (f. 1950)}

er avdelingsoverlege ved Laboratoriemedisin, Universitetssykehuset Nord-Norge og professor II ved Institutt for medisinsk biologi, Det helsevitenskapelige fakultet, Universitetet i Troms $\varnothing$. Han er leder for referansegruppen for Miljøgiftlaboratoriet ved Laboratoriemedisin, Universitetet i Troms $\varnothing$ - Norges arktiske universitet.

Forfatter har fylt ut ICMJE-skjemaet og oppgir ingen interessekonflikter.

\section{Henrik S. Huitfeldt (f. 1953)}

er professor og overlege ved Avdeling for patologi, Oslo universitetssykehus, Universitetet i Oslo.

Forfatter har fylt ut ICMJE-skjemaet og oppgir ingen interessekonflikter.

\section{Anne-Lise Bjørke Monsen (f. 1959)}

er overlege ved Laboratorium for klinisk biokjemi, Haukeland universitetssykehus, og spesialist i barnesykdommer og i medisinsk biokjemi.

Forfatter har fylt ut ICMJE-skjemaet og oppgir ingen interessekonflikter. 


\section{Litteratur}

1. Persistent Organic Pollutants. A Global Issue, A Global Response. Unites States Environmental Protection Agency 2009. www.epa.gov/internationalcooperation/persistent-organic-pollutants-globalissue-global-response (1.7.2016).

2. Grandjean P. Landrigan PJ. Neurobehavioural effects of developmental toxicity. Lancet Neurol 2014; 13: 330-8

3. Kvalem HE, Knutsen HK, Thomsen $\mathrm{C}$ et al. Role of dietary patterns for dioxin and PCB exposure. Mol Nutr Food Res 2009: 53: 1438-51.

4. Patandin S, Dagnelie PC, Mulder PG et al. Dietary exposure to polychlorinated biphenyls and dioxins from infancy until adulthood: A comparison between breast-feeding, toddler, and long-term exposure. Environ Health Perspect 1999: 107 45-51.

5. Dioksiner og dl-PCB - faktaark. Folkehelseinstituttet, oppdatert 2015. www.fhi.no/ml/miljo/ miljogifter/dioksiner-og-dl-pcb---faktaark/ (7.4.2016)

6. Berg V, Nøst TH, Huber S et al. Maternal serum concentrations of per-and polyfluoroalkyl substances and their predictors in years with reduced production and use. Environ Int 2014: 69. 58-66.

7. Bratlid D. Miljøgifter i morsmelk. Tidsskr Nor Legeforen 2009; 129: 2606-9

8. Thomsen C, Haug LS, Stigum $\mathrm{H}$ et al. Changes in concentrations of perfluorinated compounds, polybrominated diphenyl ethers, and polychlorinated biphenyls in Norwegian breast-milk during twelve months of lactation. Environ Sci Technol 2010; 44 9550-6.

9. Caspersen $\mathrm{IH}$, Kvalem HE, Haugen $M$ et al. Determinants of plasma PCB, brominated flame retardants, and organochlorine pesticides in pregnant women and 3 year old children in The Norwegian Mother and Child Cohort Study. Environ Res 2016; 146: $136-44$

10. Vandenberg LN, Colborn T, Hayes TB et al. Hormones and endocrine-disrupting chemicals: lowdose effects and nonmonotonic dose responses. Endocr Rev 2012; 33: 378-455.

11. Faroon O, Ruiz P. Polychlorinated biphenyls: New evidence from the last decade. Toxicol Ind Health 2015; 32: 1825-47.
12. Lee D-H, Steffes MW, Sjödin A et al. Low dose organochlorine pesticides and polychlorinated biphenyls predict obesity, dyslipidemia, and insulin resistance among people free of diabetes. PLOS One 2011; 6: e15977.

13. Vrijheid M, Casas M, Gascon M et al. Environmental pollutants and child health-A review of recent concerns. Int J Hyg Environ Health 2016; 219: $331-42$

14. Govarts E, Nieuwenhuijsen M, Schoeters G et al. Birth weight and prenatal exposure to polychlorinated biphenyls (PCBs) and dichlorodiphenyldichloroethylene (DDE): a meta-analysis within 12 European Birth Cohorts. Environ Health Perspect 2012; 120: 162-70.

15. Caspersen $\mathrm{IH}$, Haugen M, Schjølberg $\mathrm{S}$ et al. Maternal dietary exposure to dioxins and polychlorinated biphenyls (PCBs) is associated with language delay in 3year old Norwegian children. Environ Int 2016; 91: 180-7.

16. Meeker JD. Exposure to environmental endocrin disruptors and child development. Arch Pediatr Adolesc Med 2012; 166: 952-8

17. Karlsen M, Grandjean P. Weihe P et al. Early-life exposures to persistent organic pollutants in relation to overweight in preschool children. Reprod Toxicol 2016. E-publisert 3.8.2016.

18. Legler J, Fletcher T, Govarts E et al. Obesity, diabetes, and associated costs of exposure to endocrine-disrupting chemicals in the European Union. J Clin Endocrinol Metab 2015: 100: 1278-88

19. Stratakis N, Roumeliotaki T, Oken E et al. Fish intake in pregnancy and child growth: a pooled analysis of 15 European and US birth cohorts. JAMA Pediatr 2016: 170: 381-90.

20. Opinion of the SCF on the risk assessment of dioxins and dioxin-like PCBs - update May 2001 European Commission, Scientific Committee on Food 2001. http://ec.europa.eu/dgs/health foodsafety/committees/scientific/index_en.htm (4.7.2016)

21. Brantsæter A, Haugen M, Haugen R et al. Diet matters, particularly in pregnancy - Results from MoBa studies of maternal diet and pregnancy outcomes. Nor Epidemiol 2014; 24: 63-77.

22. Stølevik SB, Nygaard UC, Namork E et al. Prenata exposure to polychlorinated biphenyls and dioxins from the maternal diet may be associated with immunosuppressive effects that persist into early childhood. Food Chem Toxicol 2013: 51: 165-72.

23. Iszatt N, Stigum H, Govarts E et al. Perinatal exposure to dioxins and dioxin-like compounds and infant growth and body mass index at seven years: A pooled analysis of three European birth cohorts. Environ Int 2016: 94: 399-407.

24. Commission Regulation (EC) No. 1881/2006 of 19 December 2006 setting maximum levels for certain contaminants in foodstuffs. http://eur-lex.europa. eu/legal-content/EN/TXT/?uri=celex: 32006R1881 (4.7.2016).

25. Schecter A, Colacino J, Haffner D et al. Perfluorinated compounds, polychlorinated biphenyls, and organochlorine pesticide contamination in composite food samples from Dallas, Texas, USA Environ Health Perspect 2010; 118: 796-802.

26. Perelló G, Gómez-Catalán J, Castell V et al. Assessment of the temporal trend of the dietary exposure to PCDD/Fs and PCBs in Catalonia, ove Spain: health risks. Food Chem Toxicol 2012; 50: $399-408$

27. Nasjonalt institutt for ernærings- og sjømatforskning. Sjømatdata. https://nifes.no/sjomatdata-3/ (19.8.2016)

28. Haddad S, Ayotte P, Verner M-A. Derivation of exposure factors for infant lactational exposure to persistent organic pollutants (POPs). Regul Toxicol Pharmacol 2015; 71: 135-40.

29. Kortenkamp A. Ten years of mixing cocktails: a review of combination effects of endocrine-disrupting chemicals. Environ Health Perspect 2007 115 (suppl 1): 98-105

30. Woolf AD, Sibrizzi C, Kirkland K. Pediatric Environmental Health Specialty Units: An Analysis of Operations. Acad Pediatr 2016; 16: 25-33.

Mottatt 14.11. 2016, førsterevisjon innsendt 14.12. 2016, godkjent 22.12. 2016. Redaktør: Ketil Slagstad. 